\title{
COMMON GOLDENEYES and the Emma Lake Nest Boxes
}

\author{
By MAUREEN REVER and RICHARD S. MILLER
}

The Common Goldeneye or "Whistler", like the Wood Duck and the Bufflehead, nests in holes in trees. The nest site is often an abandoned woodpecker hole but may be any of a variety of natural cavities, such as the hollowed out top of a broken tree trunk. Goldeneye nests have been found as high as 60 feet above the ground but are more commonly built from 6 to 30 feet high. ${ }^{2}$ There is no apparent preference for a particular species of tree; one female goldeneye even nested successfully in a house chimney at Camrose, Alberta. " ${ }^{7}$ The nest is lined with down which the female plucks from her breast, increasing the amount with each egg that is laid. Because of a tendency for more than one female to lay eggs in the same nest, it is difficult to determine the normal clutch size of a single hen and there is considerable variation in the clutch size as reported for this species. " 3 An average clutch of 10 for 53 nests in which incubation was completed was reported from Finland, and most authors report a range of 6 to 12 for a normal clutch." There are, however, several records of nests containing 18 to 20 eggs and some cases of 30 and even 40 eggs in a single nest. A nest of 30 eggs in which 12 hatched was found in Russia, but P. Grenquist found that large clutches were usually "dump nests", nests in which more than one female laid eggs that were unincubated. 1:3 Dump nesting occurs in several species of waterfowl, but little is known about its evolutionary origins or its ecological consequences. It is presumed by some authors to be related to competition, especially among young females, for a limited number of nest sites.": The incubation period for goldeneyes has not been accurately

*Biology Dept., University of Saskatchewan, Saskatoon, and Brantford, Connectcuit measured, but it is probably between 26 and 30 days."

The numbers of many hole-nesting species are probably controlled by the number of available nest sites, and observations of intense competition for nest cavities among goldeneyes indicate that this may be a limiting factor in this species. ${ }^{2}$ is :3 It would appear, therefore, that artificial nest boxes might increase the nesting success and population size of goldeneyes, as well as provide a convenient means of studying the reproductive ecology of an interesting but little understood species.

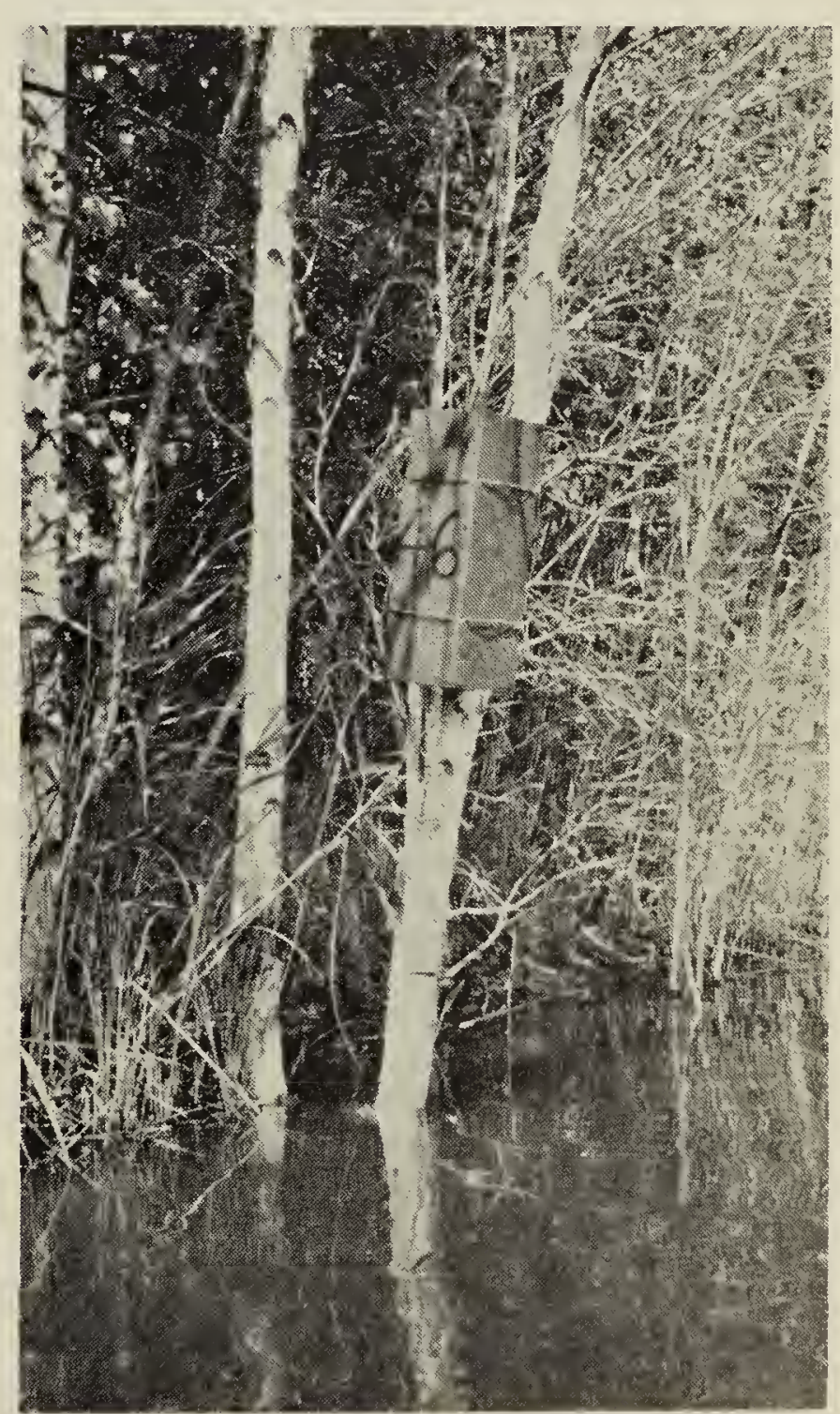


There is a long history of the use of nest boxes for goldeneyes in Scandanavia. Linnaeus, in his tour of Lapland in 1753, was the first to call attention to the tradition of the natives in northern Finland of placing nest boxes in trees to attract goldeneyes, Goosanders and Smews. In Finland the boxes are called "Tylla", which is apparently derived from "Fogel Tulle", a word that was once used to refer to rolled pieces of birch bark that were used as floats for fish nets." This suggests that the early nest boxes that were used by the Finns were merely rolled pieces of birch bark placed in trees, although the boxes that are currently used throughout Scandinavia are usually hollowed sections of tree trunk about 2 feet long with a hole in the side large enough to admit a man's hand. The box is labelled with the owner's name and is hung by a peg on a tree facing the nearest water. It is positioned so that there are no branches or other obstructions in front of the entrance hole, as the hen goldeneye flies directly into the nest without landing. With progressive deforestation in Finland and other parts of Scandinavia and the Soviet Union, Goldeneyes have become increasingly dependent on nest boxes.

In view of the many different kinds of natural sites that goldeneyes have been found to use, it is not surprising that they will also accept a variety of artificial nest boxes. Goldeneyes have used nest baskets placed in willows for Mallards and Philip Oulds has used nest boxes constructed from 5-gallon paint cans at Delta, Manitoba. ${ }^{8}$ The nest cans used by Oulds are 24 inches high and 11 inches in diameter with a 4 -inch hole 3 inches from the top of the can; the interior is painted with auto undercoating to provide a foothold for the ducklings when they leave the nest. Observations by the junior author at Delta, Manitoba, in 1972 showed that 10 of 13 nest cans were occupied by goldeneyes and that at least seven contained normal clutches.

In the summer of 1965 we placed 14 nest boxes for goldeneyes on Fairy Island at Emma Lake, Saskatchewan. Seven of the boxes were installed on Lindner Point, an area of about 3 acres,

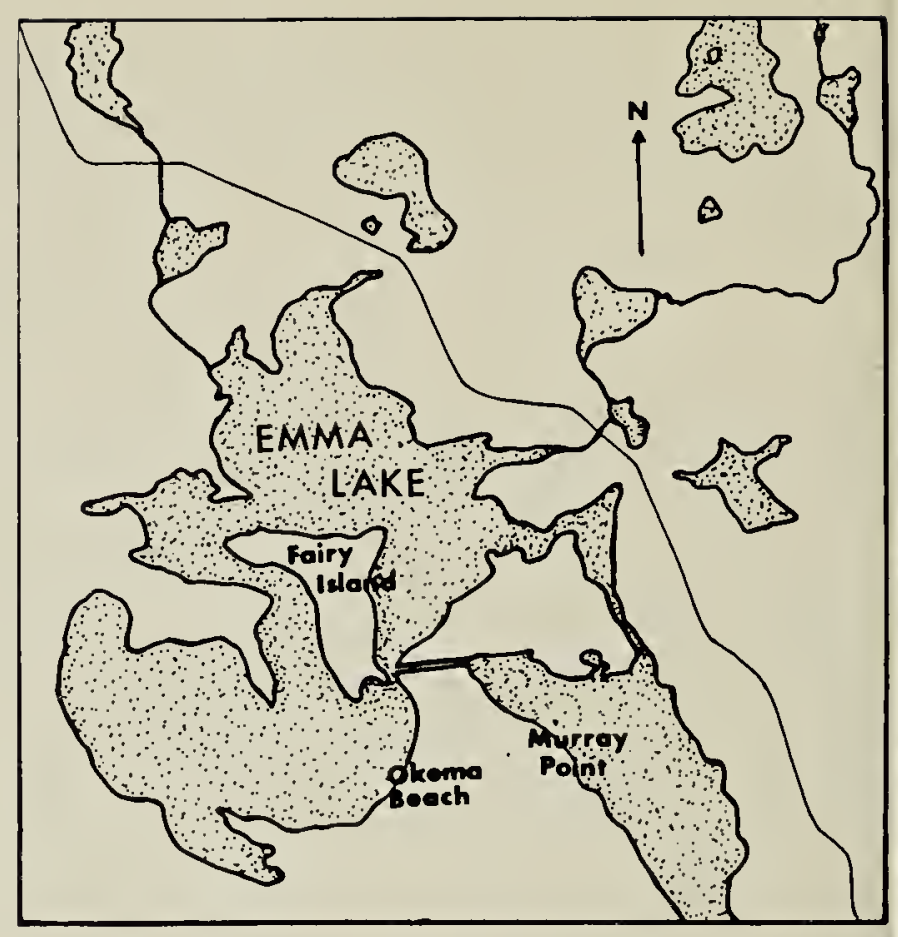

and the remaining seven boxes were located at 100-yard intervals aiong the north shore of the island. The boxes are made of $71 / 2 \times 3 / 4$-inch rough spruce boards and are 24 inches deep with inside dimensions of $6 \times 71 / 2$ inches. The bottom of the box is covered with $1 / 2$ inch hardware cloth for drainage and each box is filled to a depth of about 3 inches with coarse wood shavings or moss and leaf litter. When the boxes were first installed, they were all of the side-entry type, with a hinged lid and an entrance hole 5 inches in diameter $31 / 2$ inches below the top of the box. However, A. J. Erskine (personal communication) advised that Buffleheads readily accept open-topped, chimneytype boxes as well as side-entry boxes, and that goldeneyes would probably do the same, so in 1966 eight of the boxes were modified to the chimneytype by removing the hinged lid and covering the side-entry hole with plywood. This modification was made for several reasons: (1) none of the 1965 boxes were occupied in 1966 and it seemed advisable to provide more than one type of box, (2) most of the natural nest sites that have been found on the island are chimney-type holes in the tops of dead tree trunks, and (3) the chimney-type boxes, if suitable, are the easiest to build and maintain. Our subsequent observations have shown no significant difference in acceptance or nesting success between the two types of 
box, and all of the boxes we have installed more recently have been the chimney type. The boxes are wired to the trunks of mature American White Birch, White Spruce or Balsam Poplar about 8 to 12 feet above the ground. Most of the boxes are located on an ice ridge along the shore of the island, within sight of water, but two boxes are in natural clearings in the interior of Lindner Point.

None of the boxes was occupied by goldeneyes in 1966 and 1967, but a brood of Saw-Whet Owls was reared in a side-entry box in a birch tree in 1967. In 1968 two broods of goldeneyes were hatched in chimney-type boxes and another brood of Saw-Whet Owls was found in the same box this species occupied in 1967. There are no records for 1969 or 1970.

Table 1 shows the use of nest boxes by goldeneyes at Emma Lake in 1971 and 1972. Ten of the boxes were checked on May 29 and all 14 were inspected on September 11,1971 . It is unlikely that all clutches were complete when the boxes were examined in May 29, so that the data for 1971 are not an accurate indication of clutch size. We can state,

\section{TABLE 1.}

Use of nest boxes by Common Goldeneyes at Emma Lake, Saskatchewan, in 1971 and 1972.

1971

1972

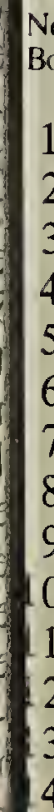

$\begin{array}{rcrc}\begin{array}{c}\text { Clutch } \\ \text { Size }\end{array} & \text { Hatched } & \begin{array}{c}\text { Clutch } \\ \text { Size }\end{array} & \text { Hatched } \\ 6 & 6 & 17 & 0^{*} \\ 12 & 12 & 14 & 14 \\ 12 & 12 & 17 & 0^{*} \\ 13 & 0^{*} & 7 & 7 \\ 5 & 5 & 11 & 11 \\ 5 & 0 & 0 & - \\ 16 & 0^{*} & 9 & 9 \\ 12 & 12 & 17 & 15 \\ 0 & - & 15 & 15 \\ 17 & 0 * & 13 & 0 * \\ ? & - & 0 & - \\ 8 & 8 & 6 & 0 \\ 12 & 0 * & 13 & 12 \\ ? & - & 13 & 0 * \\ & & & \end{array}$

Dump Nest however, that at least 11 of the 14 boxes were occupied and that there were five successful clutches, two apparently normal clutches that did not hatch, and four dump nests. A "dump nest" is one in which the rate of egg deposition is greater than one egg per day." The following criteria have also been used: (1) clutches are abnormally large, (2) there is little or no natural down in the nest, (3) the eggs are left uncovered, and (4) the eggs are cold. ${ }^{4}$ We did not inspect the nests in this study often enough to determine the rate of egg deposition, but our classification of a dump nest conforms generally to the other criteria. ${ }^{4}$ When a goldeneye hen leaves the nest without being flushed, she covers the eggs with a loose blanket of down; if she is flushed during a nest box inspection, she does not have the time to cover the eggs, but the eggs are warm. The nests we have classified as dump nests contained abnormally large clutches, the eggs were cold and were not covered with down, and there was no instance of a hen's being flushed. The dump nests that were found in 1971 were emptied and the eggs discarded after the laying period; we did not attempt to determine whether the eggs had been incubated or whether they were fertile.

The nest boxes were inspected more frequently in 1972. Each box was checked on May 25, 1972, and was visited at least once and usually three times during the period of egg laying. All clutches were apparently complete by June 2, 1972. As in 1971, obvious dump nests were emptied, but this did not result in subsequent occupany of the box by a hen with a normal clutch. The boxes were inspected again on July 5 , 1972, to determine nesting success. The results for 1972 are also shown in Table 1. Only two of the 14 boxes were unoccupied in 1972 and at least seven had successful clutches.

It was noted earlier that more than one hen will sometimes use the same nest. In 1972 the eggs in each nest were individually numbered with a felt pen and the length and maximum breadth of each egg was measured to the nearest millimeter. When there were apparent differences in colour or shape, as well as 
size, among eggs in a nest, these characteristics were also noted. It was clear from such observations that more than one female contributed to clutches which were incubated, as well as to dump nests. For example, nest box No. 9 contained an unusually large clutch of 15 eggs (Table 1), including at least two eggs which were much smaller than the others. Two small eggs, presumably from the same female, were also found in a clutch of 17 eggs in nest box No. 8, and adjacent box. The entire clutch in nest box No. 9 hatched successfully and the two eggs which failed to hatch in nest box No. 8 were not the small eggs, but were of the same size and shape as the average for this clutch. These data will be analysed in more detail later and further observations will be made in subsequent years, but we can tentatively conclude from these and similar observations of other nests that one hen may incubate and hatch eggs of other females that are laid in her nest, and that the clutch of a single hen can only be determined from careful measurement and analysis of the size, colour and shape of all of the eggs in a nest.

In spite of the time lag between the first installation of nest boxes and their subsequent use by goldeneyes at Emma Lake, we have been sufficiently encouraged by their recent success to ex- pand this study. In the summer of 1971 the number of nest boxes were increased to 33 and 19 more were added in the spring of 1972 , so that there is now a total of 52 nest boxes at Emma Lake. In addition to contributing to the welfare of this interesting duck, we feel that studies such as this will answer some of the many questions that still exist about the ecology and behaviour of goldeneyes.

'Bannerman, D. A. 1958. The birds of the British Isles. Oliver and Boyd, Edinburgh and London. Vol. 7. $256 \mathrm{pp}$.

${ }^{2}$ Brewster, W. 1900. Notes on the breeding habits of the American Golden-eyed Duck or Whistler (Clangula clangula americana). Auk 17: 207-216.

${ }^{3}$ Grenquist, P. 1963. Hatching losses of Common Goldeneyes in the Finnish Archipelago. Proc. XIII Internat. Ornithol. Congr. 685-689.

'Leopold, F. 1951. A study of nesting Wood Ducks in Iowa. Condor, 53: 209-220.

"Morse, T. E., and H. M. Wight. 1969. Dump nesting and its effect on production of Wood Ducks. J. Wildl. Mgmt. 33: 284-293.

"Phillips, J. C. 1925. A natural history of the ducks. Houghton Mifflin Co., Cambridge. Vol. 3. 383 pp.

'Prince, H. H. 1968. Nest sites used by Wood Ducks and Common Goldeneyes in New Brunswick. J. Wildl. Mgmt. 32: 489-500. '

'Titman, R. D., and J. K. Lowther. 1971. Parasitism of Mallard nests by Common Goldeneyes. Canad. Field. Nat. 85: 323-324.

"Witherby, H. F., F. C. R. Jourdain, F. Ticeburst, and B. W. Tucker. 1939. The handbook of British Birds. H. F. and G. Witherby Ltd., London. Vol. 3. 387 pp.

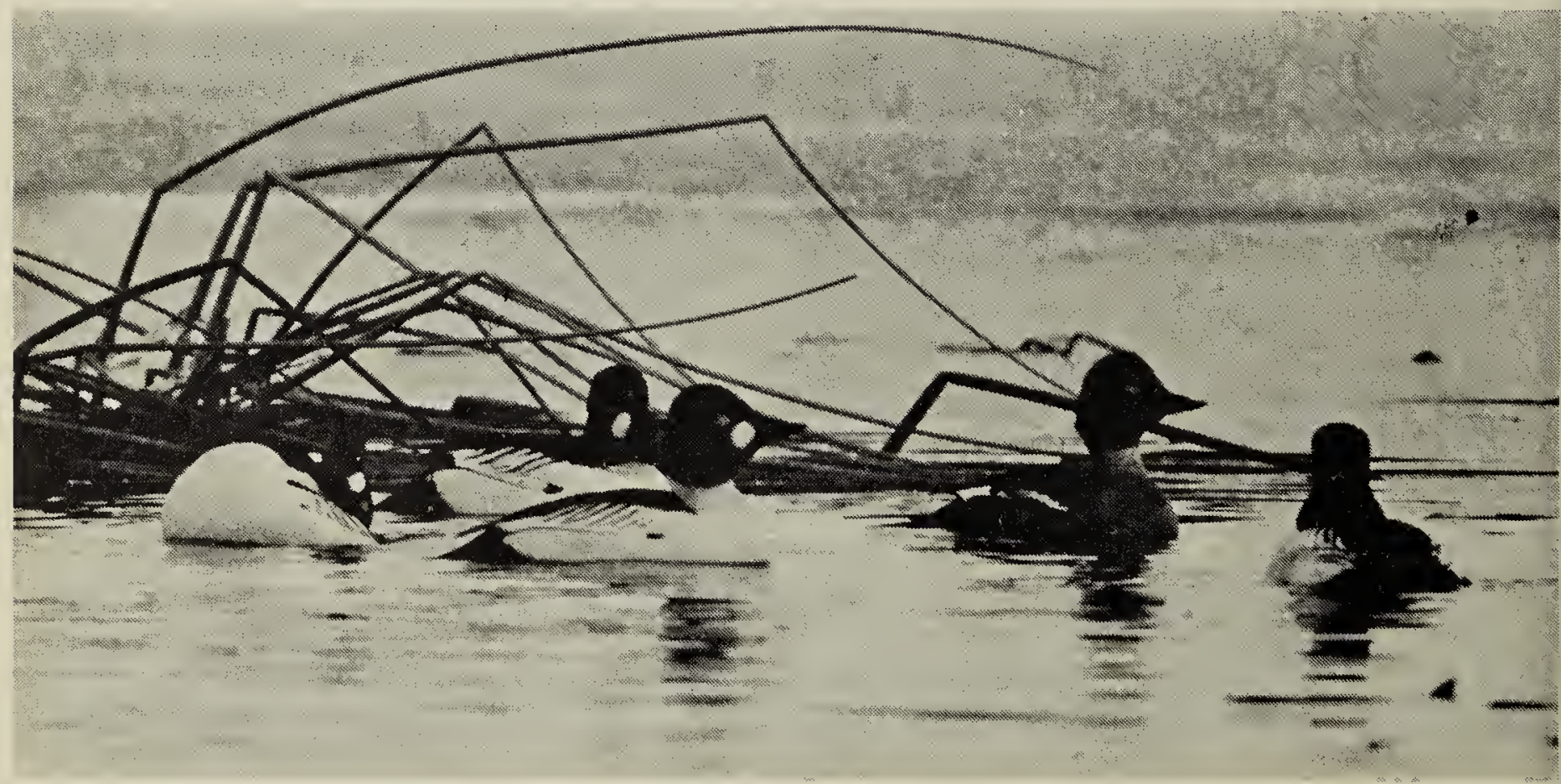

